\title{
Cancer by UV radiation from nanoparticles in GM food
}

\author{
Thomas Prevenslik* \\ QED Radiations, Hong Kong, China
}

\begin{abstract}
The causal link between GM food and human health is proposed to be the scrambling of genes in DNA by low-level UV radiation. GM stands for genetically modified. Modern agriculture controls weeds by spraying Roundup containing water and Glyphosate onto crop fields. To enhance Glyphosate penetration through weed leaves, the adjuvant POEA is added to Roundup. POEA stands for polyoxyethyleneamine. But weeds alone cannot be sprayed and POEA also enters the leaves of corn and soybean crops as an emulsion of NP globules that ultimately reside in the plant crop. NP stands for nanoparticle. Upon ingestion of GM food, body heat is thought to increase the NP temperature. But this is a consequence of classical physics when in fact QM governs the nanoscale. QM stands for quantum mechanics that requires the heat capacity of NPs to vanish. Conservation of body heat in NPs therefore cannot occur by the usual increase in temperature and instead proceeds by the emission of UV radiation. Nearby DNA are damaged and if the scrambled genes are not repaired by the immune system may lead to cancer. The UV radiation from NPs supports experiments over the past decade that show NPs damage the DNA. But GM food is planned for future world-wide consumption raising the question of whether cancer as a crime against humanity is being committed on the people of the world by altering their DNA.
\end{abstract}

\section{Introduction}

Herbicide-resistant weeds now plague more than 60 million acres of US farmland. To control weeds, the non-selective herbicide Glyphosate including an adjuvant to enhance the penetration through weed leaves is widely sprayed on crop fields. But it is not possible to spray weeds alone, and therefore Glyphosate enters crop plants and ultimately resides in soy and corn crops.

Herbicide adjuvants [1] include the surfactant POEA including a declared AP which is often proprietary and kept confidential by manufacturers. POEA stands for polyoxyethyleneamine and AP for application principle, e.g., in Monsanto's Roundup, the declared AP is Glyphosate while POEA is considered an adjuvant. However, the FDA only regulates the toxicity of APs. Adjuvants like POEA are classified as chemically inert and not regulated. Moreover, if the POEA in the bulk is shown to not be toxic, NPs of POEA are not considered toxic. But studies [2] based on various Roundup formulations strongly suggest that toxicity was due to adjuvants present in the formulations and not the direct result of Glyphosate. In fact, POEA alone was found more toxic.

Upon human ingestion of GM foods, most Glyphosate and POEA are rapidly excreted, but residues remain in the gut. Of great controversy today is whether the residues are harmful to human health. Donald Huber, the prominent critic of GM foods claims [3] a pathogen is produced from Glyphosate that harms human health, e.g., residents living close to sprayed GM soybean fields in Argentina developed cancers and birth defects. However, GM food proponents argue science is still looking for, but not found Huber's pathogen to establish the causal link between Glyphosate and human health. Regardless, a single pathogen linking GM food to human health is unlikely because the diversity of problems, e.g., birth defects, autism, and so forth can only be caused by different pathogens.

One such source of different pathogens is the DNA damage from NPs. NPs stand for nanoparticles having dimensions $<100 \mathrm{~nm}$. Consistent with adjuvants enhancing the penetration of Glyphosate through weed and crop plant leaves, experiments [4] show POEA upon mixing in water form a emulsion of globular NPs that adhere to and forms films on surfaces. Hence, the toxicity of POEA is proposed to be the globular NPs that attach to and disrupt cell walls allowing Glyphosate to enter and damage the DNA. If so, the scrambling of genes would lead to a variety of observed health problems. However, it is not clear how inert POEA globules disrupt cell walls or otherwise damage the DNA.

But DNA damage by NPs is not new. Over the past decade, lung cancer based on in vivo and in vitro models $[5,6]$ show NPs induce oxidative stress and pro-inflammatory effects. At that time, the mechanisms of the generation of the oxidative stress by NPs was not understood, but thought in some way related to the large S/V ratios. $\mathrm{S} / \mathrm{V}$ stands for surface-to-volume. In 2008, the DNA damage was thought [7] linked to cancer by ROS from respiration and metabolism. ROS stands for reactive oxygen species. ROS include the highly reactive hydroxyl radicals linking the activation of $\mathrm{p} 53$ and proteins related to DNA repair thereby mimicking irradiation-related carcinogenesis pathways. But the literature has never identified how NPs produce EM energy of at least $5 \mathrm{eV}$ to create the hydroxyl radicals.

It was not until 2010 that NPs were proposed $[8,9]$ to provide the EM energy necessary to create the ROS. Indeed, NPs were shown to create the ROS by providing a natural low-level source of continuous EM radiation beyond the UV. Here, UV stands for ultraviolet. At that time, the source of EM radiation transferred to the NPs was by molecular collisions, but since then has been superseded by any form of NP heating from the surrounding tissue. At UV levels, the NPs have sufficient EM energy at $5 \mathrm{eV}$ levels to create the ROS that damage

Correspondence to: Thomas Prevenslik, QED Radiations, Discovery Bay, Hong Kong, China, Tel: +(49)2723257678, E-mail: thomas@nanoqed.org/ nanoqed@gmail.com

Key words: GM food, DNA damage, UV radiation, nanoparticles, classical physics, quantum mechanics

Received: December 19, 2016; Accepted: January 10, 2017; Published: January 14,2017 
nearby DNA. However, the ROS are no longer necessary as DNA damage in the irradiation-related carcinogenesis pathways are in fact activated by UV radiation.

Today, the cancer pathways linked to NPs continues to be based on ROS and not UV radiation. Recently, silver NPs linked to ROS were studied [10] in the protein interaction of the human LoVo cell line and found to depend on NP size. The $100 \mathrm{~nm}$ NPs indirectly effected serine/threonine protein kinase (PAK) and mitogen-activated protein kinase (MAPK), and phosphatase 2A pathways; whereas, the $20 \mathrm{~nm}$ NPs directly affect cellular stress and generation of ROS and protein carbonylation. But the presence of $\mathrm{Ag}+$ ions suggest the NPs are producing UV radiation $>5 \mathrm{eV}$ necessary to ionize silver. Indeed, the bactericidal action of silver NPs suggests UV radiation is being produced that causes [11] chromosomal damage in human hepatocarcinoma cells (HepG2) rather than by the ROS from the release of $\mathrm{Ag}$ and subsequent oxidation to $\mathrm{Ag}+$.

The UV in the UVC at $254 \mathrm{~nm}$ is a lethal level for DNA damage in all living systems as the pyrimidine dimers are formed [12] that block DNA replication. If the scrambled genes are not repaired, human diseases of cancer and birth defects may occur. After all, the collateral damage of silver NPs as a bactericidal agent should not be expected to not damage DNA.

In this paper, the causal link between GM foods and varied human health problems is proposed to be the scrambling of genes in DNA by UV radiation from NPs of POEA globules that diffuse through the cell wall. Upon attaching to cell walls, the UV radiation may also disrupt cell walls by ionizing wall molecules allowing Glyphosate to enter and damage the DNA. But the DNA damage need not be limited to GM food that upon ingestion produce NP globules of POEA. Indeed, the effects of NPs in nano-medicine, e.g.,

Drug delivery vehicles, Antimicrobial agents, Treating cancer in photodynamic therapy are placed in question unless the attendant DNA damage leading to human health problems is justified alongside the celebrated beneficial effects of NPs .

\section{Materials and methods}

\section{Planck law}

The UV radiation from globular POEA NPs may be readily understood. Classically, NP atoms have heat capacity and conserve body heat by increasing in temperature. But QM governs the nanoscale. QM stands for quantum mechanics. The Planck law of QM [13] for the atom at $300 \mathrm{~K}$ is shown in figure 1.

Figure 1 shows QM allows the atom in macroscopic matter to have $k T$ energy and behave classically by increasing in temperature upon absorbing heat under EM confinement at $\lambda>100$ microns. NPs of nanoscopic matter differ as the $k T$ energy decreases for atoms having EM confinement $\lambda<100$ microns, and for NPs having $\lambda<100 \mathrm{~nm}$ the atoms have virtually no heat capacity to conserve absorbed heat by an increase in temperature.

Despite the fact the Planck law is known for over a century, nanotechnology today continues to assign finite heat capacity to NPs. In nanoparticle mass spectrometry, 20-50 nm carbon NPs are trapped in a quadrupole ion trap [14] and heated with lasers. Based on classical physics, NP temperatures increase to $3000 \mathrm{~K}$. High temperatures were thought verified by comparing the measured NP mass loss rate with the

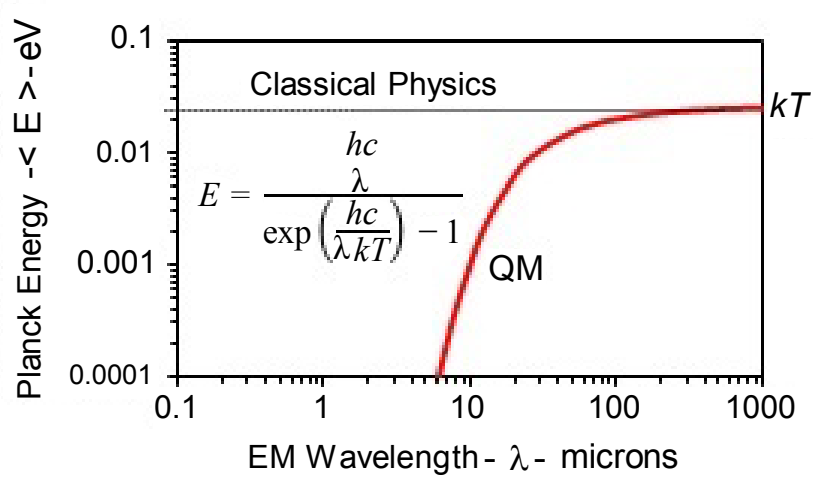

Figure 1. Planck law of the Atom at $300 \mathrm{~K}$. In the inset, $E$ is Planck energy, $h$ Planck's constant, $c$ light speed, $k$ Boltzmann's constant, $T$ temperature, and $\lambda$ the EM confinement wavelength

temperature estimated from known sublimation rates vs temperature for bulk polycrystalline graphite. But figure 1 shows the heat capacity for carbon NPs vanishes while that for bulk graphite at $\lambda>100$ microns is finite. Hence, high temperatures do occur in the bulk, but NPs cannot change in temperature. Lack of temperature change suggests mass loss in NPs is caused by fragmentation under charge induced Coulomb repulsion.

\section{EM Confinement}

QM by the Planck law requires the NP atoms have vanishing heat capacity thereby precluding conservation by temperature changes. For heat capacity to vanish, the NP atoms must somehow be placed under nanoscale EM confinement. NP surfaces lack any texture that could be construed as EM confinement. But NPs have high S/V ratios that confine body heat almost entirely to their surfaces, the surface heat thereby providing the necessary EM confinement of NP atoms over nanoscale wavelengths. S/V stands for surface-to-volume. QED then conserves the surface heat by creating EM radiation standing between diametrically opposite NP surfaces.

\section{Simple QED}

Simple QED differs from the complex relativistic QED [15] by Feynman and others. Briefly stated: QED conserves heat supplied to a NP absent heat capacity by creating EM radiation having halfwavelength $\lambda / 2=d$, where $d$ is the diameter of the NP. The Planck energy $E$ of the standing EM radiation is:

$$
E=h\left(\frac{c}{n}\right) / \lambda=\frac{h c}{2 n d}
$$

where, the velocity of light $c$ is corrected for the slower speed in the solid state by the refractive index $n$ of the NP.

QED induced EM radiation differs from the speculative multi - IR photon [16] processes that excite dopant atoms, i.e., the QED radiation depends only on the NP size and refractive index. DNA damage from QED induced EM radiation is therefore always expected as the absorption of heat by a NP is excited from (1) in the EUV at wavelength $\lambda=2 n d$. EUV stands for extreme ultraviolet. Dopant atoms in lower quantum states are excited by EUV fluorescence [17] as the NP gives up EUV energy by radiationless processes. QED induced EM radiation thereby avoids the highly unlikely multi-photon process. 


\section{POEA surfactant}

The FDA classifies Glyphosate as the AP in Roundup and claims [2] it is not toxic for human cells, except when mixed with inert components such as POEA surfactant. However, POEA causes AK and SD in human cells. AK stands for membrane damage and SD for mitochondrial activity leading to cell mortality. POEA globules may diffuse through cell walls, although the mechanism by which AK and $\mathrm{SD}$ occur is not identified in the literature.

\section{$\mathrm{AK}$ and SD mechanism}

The proposed AK and SD mechanism is the EM radiation from NPs of POEA globules. Although the literature does not show NP globules in Roundup, POEA globules are known [4] to aggregate in water and adhere to glass surfaces to form nanoscale films. By analogy, POEA globules may adhere to cell surfaces and diffuse or burrow through the cell wall as shown in figure 2.

In POEA globular NPs, body heat is converted to EM radiation beyond the UV allowing burrowing to occur by ionization of the cell wall. Glyphosate then may enter the disrupted cell wall to damage the DNA. However, the DNA may also be damaged by UV radiation from POEA globules that simply passes through cell walls.

\section{Energy of QED induced EM radiation}

The EM radiation energy depends on the POEA globule size. For a POEA of ethylene amine having refractive index $n=1.51$, the Planck energy $E$ of QED induced radiation in terms of the diameter $d$ of the POEA globules is shown in figure 3.

\section{Toxicity}

The toxicity of Glyphosate in human cells is enhanced by the disruption of membrane walls by ionizing QED induced EM radiation. Figure 3 shows the Planck energy $E$ varies from 20 to $4 \mathrm{eV}$ for POEA globule diameters $d$ from 20 to $100 \mathrm{~nm}$, respectively. Hence, the QED induced EM radiation from POEA globules is more than sufficient to ionize wall molecules thereby enhancing the toxicity $[1,2]$ of Glyphosate by diffusing into the human cell.

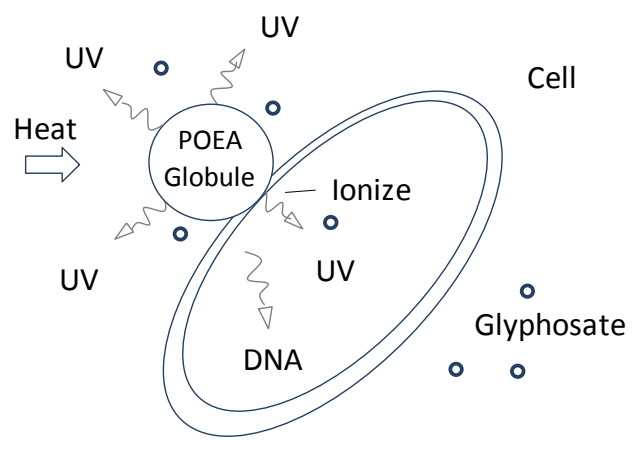

Figure 2. POEA Globule producing UV Radiation.

\section{Results}

Over 100 Nobel Laureates signed a letter [18] made public urging Greenpeace to review its claims that crops and foods worldwide are not improved with biotechnology, recognize the contrary claims of scientific bodies and regulatory agencies, and abandon their campaign against GM food in general and Golden Rice in particular.

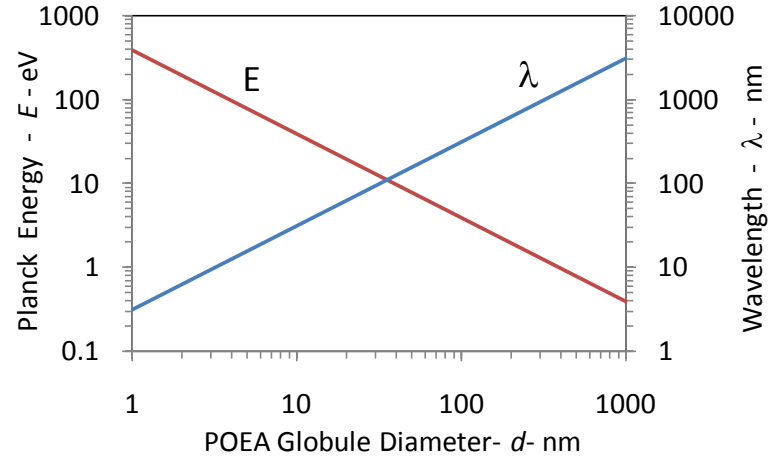

Figure 3. POEA globule energy and wavelength.

Greenpeace has led the opposition to Golden Rice, which has the potential to reduce or eliminate much of the death and disease caused by VAD having the greatest impact on the poorest people in the world. VAD stands for vitamin A deficiency. The WHO estimates over 250 million people suffer from VAD which compromises the immune system, putting children at great risk.

The Laureates ask the governments of the world to reject [19] Greenpeace's campaign against Golden Rice and GM foods in general and oppose Greenpeace's actions and accelerate the access of farmers to modern biology, especially GM seeds improved through biotechnology. The letter argues that Greenpeace by misrepresenting the risks of GM food based on emotion and dogma is contradicted by science, and therefore must stop.

The letter campaign was organized by Richard Roberts and Phillip Sharp, co-winners of the 1993 Nobel Prize in medicine for the discovery of DNA sequences known as introns. Roberts told The Washington Post:

"We're scientists. We understand the logic of science. It's easy to see what Greenpeace is doing is damaging and is anti-science,"

The Laureates letter [18] concludes alleging Greenpeace by denying GM food has placed millions of people in the developing world at risk of VAD by asking the question:

How many poor people in the world must die before we consider this a "crime against humanity"?

Clearly, emotion and dogma do not belong in science even by Nobel Laureates. The letter by the Laureates supporting the GM food industry refuting Greenpeace's actions is not based on scientific arguments, but on emotion and dogma from the GM food industry perspective.

Regardless, it is unlikely the Laureates did not know their signature to the letter would support the GM food industry argument against Greenpeace, thereby raising the question as to whether the Laureates based on their scientific expertise knew the letter was false and could only have signed the letter for personal reward, but

Is there a scientific argument that the Laureates knew or should have known that GM food may damage human health?

If so, a jury would find the Laureates did indeed sign the letter known to be false, an unfortunate act as the Nobel Laureates hold the highest esteem in science.

\section{Scientific argument}

Unlike Huber's pathogen, the scientific argument linking GM food 
to human health requires the causal relation that the human DNA is damaged from UV radiation produced from heated NPs of POEA globules in the gut, the UV radiation being unequivocally genotoxic.

\section{Legal argument}

Prior knowledge is the legal basis of a crime against humanity. Even if the Laureates did not know QM requires NPs conserve body heat by emitting EM radiation beyond the UV, the Laureates knew or should have known experiments over the past decade have shown NPs damage the DNA of all living cells that if not repaired may lead to cancer including a variety of health problems.

\section{Greenpeace vs. Nobel Laureates}

Greenpeace is most certainly not guilty of a crime against humanity. Contrarily, the GM food industry may be alleged guilty of a crime against humanity as the DNA of the people of the world is damaged by the UV radiation from NPs that if not repaired by their immune systems may give rise to cancer including the wide range of observed health problems.

The Nobel Laureates signing the letter in support of GM foods knew or should have known the scientific basis of the letter was false and therefore are complicit in the alleged crime of the GM industry against humanity.

GM food proponents should stop their campaign against the Greenpeace claim that GM food is harmful to human health as DNA damage from NPs cannot be scientifically denied. Instead, the GM food industry should label the NPs in their products to allow the consumer to make an informed decision on its purchase.

\section{Conclusions}

QED induced radiation from NPs is a consequence of QM that negates heat capacity of the atom under nanoscale EM confinement thereby requiring the conservation of body heat by emitting EM radiation beyond the UV that damages the DNA.

The causal link between ingested GM foods and human health is the scrambling of genes in DNA damage by UV radiation from POEA globular NPs in Glyphosate residues. Only genotoxicity can link GM food to human health because the diversity of problems, e.g., cancer, Parkinson's disease, birth defects, and autism cannot be explained by a single pathogen.

NPs provide an important link between DNA damage by UV radiation beyond the UVC within the body. Currently, UV induced DNA damage is thought to only occur in the skin exposed to solar radiation at UVB levels. The far more DNA damaging solar UVC does not reach the Earth because of ozone absorption in the upper atmosphere. But NPs as a UVC source within the body are always damaging the DNA and should be recognized as a prime cause of human health problems.

POEA globular NPs upon diffusing through cell walls emit UVC radiation that readily travels in cellular water to damage DNA at a distance. Contact is not necessary.

The beneficial effects of NPs in nano-medicine should always include companion test results of associated DNA genotoxicity.

\section{References}

1. Mesnage R, Defarge N, Spiroux de Vendômois J, Séralini GE (2014) Major Pesticides Are More Toxic to Human Cells Than Their Declared Active Principles. BioMed Research International.

2. Benachour N, Séralini GE (2009) Glyphosate formulations induce apoptosis and necrosis in human umbilical, embryonic, and placental cells. Chem Res Toxicol 22 97-105. [Crossref]

3. Genetic Literacy Project: Don Huber. (October 2015) [Available: https://www. geneticliteracyproject.org/glp-facts/don-huber-science-still-looking-for-Purdueprofessors-gmo-pathogen-time-bomb/]

4. Leite FL, Paterno LG, Borato CE, Herrmann PSP (2005) Study on the adsorption of poly(o-ethoxyaniline) nanostructured films using atomic force microscopy. Polymer 46: $12503-12510$

5. Donaldson K, Stone V (2003) Current hypotheses on the mechanisms of toxicity of ultrafine particles. Ann Ist Super Sanita 39: 405-410. [Crossref]

6. Donaldson K (2003) The biological effect of coarse and fine particulate matter. Occu Environ Med 60: 313-314. [Crossref]

7. Mroz RM, Schins RPF, Li H, Jimenez LA, Drost EM, et al. (2008) Nanoparticledriven DNA damage mimics irradiation-related carcinogenesis pathways. Eur Respir $J$. [Crossref]

8. Prevenslik T (2010) DNA damage by Nanoparticles. Proceedings of ASME2010 First Global Conference on Nano Engineering for Medicine and Biology, NEMB2010, Houston, TX, USA, February 7-10, 2010.

9. Prevenslik T (2010) Nanoparticle toxicity and cancer. International Conference on Safe production and use of nanomaterials, NANOSAFE 2010, Minatec, Grenoble, France, November 16-18, 2010.

10. Verano-Braga T, Miethling-Graff R, Wojdyla K, Rogowska-Wrzesinska A, Brewer JR, et al. (2014) Insights into the Cellular Response Triggered by Silver Nanoparticles Using Quantitative Proteomics. ACS Nano 8: 2161-2175. [Crossref]

11. Zhao X, Ibuki Y (2015) Evaluating the Toxicity of Silver Nanoparticles by Detecting Phosphorylation of Histone H3 in Combination with Flow Cytometry Side-Scattered Light. Environ Sci Technol 49: 5003-5012.

12. Pfeifer GP, Besaratinia A (2012) UV wavelength-dependent DNA damage and human non-melanoma and melanoma skin cancer. Photochem Photobiol Sci 11: 90-97. [Crossref]

13. Planck M (1900) On the Theory of the Energy Distribution Law of the Norma Spectrum. Verhandl Dtsch Phys Ges 2: 237.

14. Howder CR, Long BA, Gerlich D, Alley RN, Anderson SL (2015) Single Nanoparticle Mass Spectrometry as a High Temperature Kinetics Tool: Sublimation, Oxidation, and Emission Spectra of Hot Carbon Nanoparticles. J Phys Chem A 119: 12538-12550. [Crossref]

15. Feynman R (1976) QED: The Strange Theory of Light and Matter. Princeton University Press.

16. Chen G, Qiu H, Prasad PN, Chen X (2014) Upconversion nanoparticles: design, nanochemistry, and applications in theranostics. Chem Rev 114: 5161-5214. [Crossref]

17. So PTC, Dong CY (2002) Fluorescence Spectrophotometry. ENCYCLOPEDIA OF LIFE SCIENCES. Macmillan Publishers Ltd, Nature Publishing Group.

18. Roberts RJ, Sharp PA. (June 29 2016) Laureates Letter Supporting Precision Agriculture (GMOs). [Available: http://supportprecisionagriculture.org/nobel-laureategmo-letter_rjr.html]

19. Washington Post (June 29 2016) 107 Nobel laureates sign letter blasting Greenpeace. [Available:https://www.washingtonpost.com/news/speaking-of-science/ $\mathrm{wp} / 2016 / 06 / 29 /$ more-than-100-nobel-laureates-take-on-greenpeace-over-gmostance $/$ ?utm_term $=. d 768 \mathrm{ae} 13 \mathrm{ca} 7 \mathrm{~d}]$

Copyright: (C2017 Prevenslik T. This is an open-access article distributed under the terms of the Creative Commons Attribution License, which permits unrestricted use, distribution, and reproduction in any medium, provided the original author and source are credited. 